\title{
KAJIAN KONSEP ARSITEKTUR NEO VERNACULAR PADA DESA WISATA TAMANSARI
}

\author{
${ }^{1}$ Muhamad Ramanindra Wicaksono, ${ }^{2}$ Anisa \\ 1-2Universitas Muhammadiyah Jakarta, Jakarta, Indonesia \\ 2016460032@ftumj.ac.id ${ }^{1}$
}

\author{
Informasi Naskah
}

Diterima: 21/05/2020; Disetujui terbit: 29/12/2020; Diterbitkan: 29/12/2020;

http://journal.uib.ac.id/index.php/jad

\begin{abstract}
ABSTRAK
Era globalisasi atau era dunia tanpa batas telah menyentuh seluruh aspek kehidupan manusia, mulai dari teknologi informasi hingga budaya, dan tidak terkecuali dunia arsitektur. Perkembangan pola pikir yang baru dan berbeda menyebabkan banyak pembangunan suatu gedung atau kawasan menjadikan kemajuan teknologi sebagai landasan utama pembangunan dan menghilangkan nilai-nilai lokalitas, kebudayaan, dan kebiasaan suatu tempat. Kajian konsep arsitektur neo vernacular sebagai bentuk katalisator dari perkembangan teknologi dari luar dengan keadaan lokalitas, budaya, dan kebiasaan dari dalam. Desa wisata Tamansari sebagai merupakan salah satu desa wisata di Kabupaten Bogor yang masih dalam tahap pengembangan infrastruktur, baik dari konsep neo vernacular, dan akomodasi sebagai sebuah desa wisata. Penelitian dengan metode deskriptif kualitatif ini menghadirkan Desa Wisata Tamansari di Kabupaten Bogor ini sebagai sebuah etalase pembangunan desa yang telah mengikuti perkembangan zaman namun tetap mempertahankan nilai-nilai lokalitas, kebudayaan, dan kebiasaan dari dalam desa.
\end{abstract}

Kata Kunci: neo vernacular; desa wisata, tamansari, wisata budaya, ekowisata, globalisasi.

\begin{abstract}
The era of globalization or the era of the world without borders has touched all aspects of human life, ranging from information technology to culture, and the architectural world is no exception. The development of a new and different mindset causes a lot of the construction of a building or region to make technological progress as the main foundation of development and eliminate the values of locality, culture, and habits of a place. Study of neo vernacular architectural concepts as a catalyst for the development of technology from the outside with locality, culture, and habits from within. Tamansari tourism village as one of the tourist villages in Bogor Regency which is still in the stage of developing infrastructure, both from the neo vernacular concept, and accommodation as a tourist village. This qualitative descriptive method presents Tamansari Tourism Village in Bogor Regency as a window of village development that has followed the times but still maintains local values, culture, and habits from within the village.
\end{abstract}

Keywords: neo vernacular, tourism village, tamansari, tourism culture, ecotourism, globalization

\section{Pendahuluan}

Dunia tanpa batas menjadikan seluruh elemen di dunia menjadi satu kesatuan yang tak terpisahkan. Pertukaran informasi yang begitu cepat membuat orang-orang dapat 
dengan mudah mengetahui dan belajar beragam perbedaan dari satu tempat ke tempat lain, tidak terkecuali dengan perkembangan teknologi dan kebudayaan yang juga menyentuh ke aspek arsitektur.

Banyak pengembangan wilayah atau bangunan yang mengedepankan fungsi dan teknologi bangunan dengan menyampingkan budaya, nilai lokalitas, dan kebiasaan sebuah tempat. Hal tersebut sangat disayangkan karena mungkin suatu saat nanti anak cucu kita tidak mengetahui kebiasaan dan budaya yang dimiliki oleh para orangtuanya. Untuk itu, arsitektur neo vernacular menjadi sebuah konsep pendekatan yang tepat untuk tetap berkembang sesuai dengan zaman, namun tidak melupakan nilai-nilai lokalitas, kebudayaan, dan kebiasaan sebuah daerah.

Salah satu tempat yang dinilai masih menyimpan dan melestarikan kebudayaan, nilai lokalitas, dan kebiasaan daerahnya adalah desa wisata. Desa wisata merupakan gabungan interaksi dan menjadi sebuah etalase beragam keindahan yang dimiliki sebuah desa. Desa Wisata Tamansari di Kabupaten Bogor terletak di kaki gunung salak yang memiliki pemandangan indah dan udara yang sejuk. Beragam wisata desa yang dapat dinikmati secara fisik dan non fisik menjadikan sebuah integrasi pengembangan desa yang mandiri. Analisis penerapan arsitektur neo vernacular di Desa Wisata Tamansari Kabupaten Bogor bertujuan untuk mengetahui sejauh mana desa wisata telah berkembang dengan menggunakan prinsip-prinsip aristektur neo vernacular.

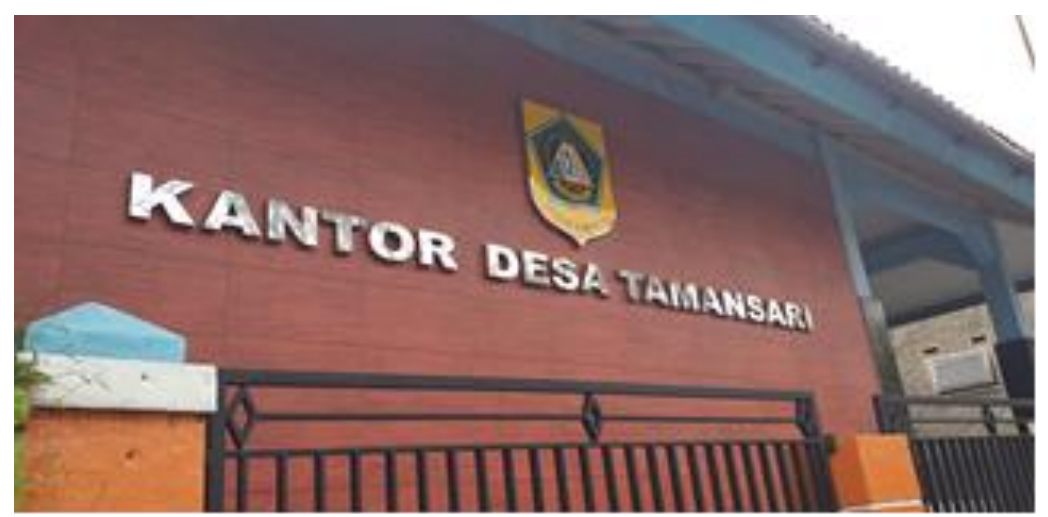

Gambar 1. Bangunan Kantor Desa Tamansari Sumber: Pribadi, 2019

\section{Kajian Pustaka}

Kajian pustaka pada penelitian ini berisi tentang pengertian, ciri-ciri, prinsip arsitektur neo vernacular dan desa wisata yang dikemukakan oleh para ahli dari beberapa sumber yang penulis sarikan yang dinilai cukup relevan dengan penelitian yang dilakukan.

\subsection{Arsitektur Neo Vernacular}

Arsitektur Neo Vernacular merupakan salah satu jawaban dari kritik terhadap gaya arsitektur era modern yang mengedepankan fungsionalisme dan rasionalisme yang dipengaruhi perkembangan teknologi. Dalam proses eksplorasi gedung-gedung ModernVernacular di Indonesia, menurut Deddy Erdiono, menyatakan bahwa ada empat model pendekatan yang harus diperhatikan terkait dengan bentuk dan makna dalam merancang dan memodernisir bangunan tradisional dalam konteks kekini-an, yaitu kecenderungan terjadinya perubahan- perubahan dengan paradigma, yaitu: (Erdiono, November 2011)

1. Bentuk dan maknanya tetap

Bentukan dan makna bangunan masih tetap. Bila ada sedikit perubahan dalam 
material penyusun bangunan itu masih diperbolehkan, sedangkan makna yang dimiliki masih sesuai dengan kosmologi, mitologi, dan genealogi yang ada.

2. Bentuk tetap dengan makna baru

Makna yang diambil merupakan makna baru yang didapat dari adopsi budaya dan nilai-nilai asing seperti mengubah makna sakral menjadi makna profan dan juga menghilangkan mitos-mitos yang ada sebelumnya. Namun, bentuk bangunan tetap sama seperti sediakala.

3. Bentuk baru dengan makna tetap

Bentuk baru dengan makna tetap maksudnya adalah sebuah makna lama yang masih sesuai dengan tradisi yang ada namun diinterpretasikan dengan cara yang baru.

4. Bentuk dan maknanya baru.

Bentuk dan makna baru biasa terjadi pada masyarakat yang berada pada masa pasca transisi yang mempunyai kebebasan untuk mengolah bentuk dan makna tanpa Batasan konservatif yang mengikat.

Menurut Sumalyo Pendekatan Arsitektur Neo Vernacular digunakan untuk mendapatkan gubahan arsitektur yang mengacu pada bahasa setempat dengan mengambil elemen-elemen fisik maupun non fisik, seperti budaya, pola pikir, kepercayaan/pandangan terhadap ruang, nilai filosofi, dan religi, menjadi konsep dan kriteria perancangan ke dalam bentuk kontemporer (Abdul Aziz Arrosyid, 2016)

Arsitektur Neo Vernacular merupakan salah satu gaya arsitektur yang termasuk dalam perkembangan zaman paska modern. Menurut Van De Ven, era paska modern identik dengan unsur religi, moral, dan etika. Segala bentuk penilaian tidak ilmiah direpresentasikan dengan bentuk arsitektural. (Rachmawati, 2010)

Menurut Zikri arsitektur neo vernacular memiliki kriteria sebagai berikut: (Ghina Fajrine, 2017)

- Bentuk-bentuk arsitektural yang menjawab keadaan budayan lingkungan, dan iklim, seperti tata letak denah, detail, dan ornamen.

- Penerapan elemen elemen non fisik setempat seperti pola pikir, kepercayaan, dan tata letak yang mengacu kepada makro kosmos lainnya.

- Bangunan neo vernacular menghasilkan sebuah gaya baru yang tidak sepenuhnya menerapkan prinsip-prinsip bangunan vernacular.

Eva mendeskripsikan karakteristik dari Arsitektur neo vernacular adalah sebagai berikut: (Eva Anggraini, April 2016)

1. Bentuk bangunan. Atap, badan, dan pondasi bangunan pada bangunan neo vernacular semuanya berkembang sesuai dengan kondisi yang terjadi. Perkembangan dapat dimulai dari segi bahan baku penyusun, system kontruksi, atau kebutuhan ruang.

2. Warna. Biasanya, bangunan yang bergaya arsitektur neo vernacular memilih warnawarna yang kontras hingga memberikan kesan yang dinamis untuk menarik pengunjung.

3. Ornamen. Makna-makna filosofis yang mungkin masih ingin disampaikan dapat disimbolkan dengan ornamen-ornamen yang diletakan di dinding, list plang, kolom, dan tempat-tempat yang mudah terlihat lain nya.

4. Material. Neo vernacular memungkinkan terjadinya penggabungan antara material lokal dengan material modern. 
Adapun beberapa prinsip-prinsip desain arsitektur Neo Vernacular menurut Brolin secara terperinci adalah sebagai berikut. (Windra Dwi Saputra, 2019)

- Hubungan Langsung, merupakan pembangunan yang kreatif dan adaptif terhadap arsitektur setempat disesuaikan dengan nilai-nilai/fungsi dari bangunan sekarang.

- Hubungan Abstrak, meliputi interprestasi ke dalam bentuk bangunan yang dapat dipakai melalui analisa tradisi budaya dan peninggalan arsitektur.

- Hubungan Lansekap, mencerminkan dan menginterpretasikan lingkungan seperti kondisi fisik termasuk topografi dan iklim.

- Hubungan Kontemporer, meliputi pemilihan penggunaan teknologi, bentuk ide yang relevan dengan program konsep arsitektur.

- Hubungan Masa Depan, merupakan pertimbangan mengantisipasi kondisi yang akan datang.

\subsection{Desa Wisata}

Menurut Hermawan, desa wisata ialah sebuah lingkungan berlatar desa yang memiliki daya Tarik berupa nilai-nilai lokalitas budaya setempat dan juga kekayaan alam. Desa wisata biasanya memiliki beberapa daerah tujuan wisata dan gabungan dari agrowisata, wisata budaya, dan ecotourism. (Hermawan, September 2016 )

Menurut Andi, desa wisata adalah sebuah desa yang memberikan kesan pedesaan alami kepada pengunjung melalui bangunan, tata ruang desa, adat istiadat, keseharian masyarakat, kehidupan sosial budaya, dan potensi kepariwisataan lain seperti atraksi budaya, atraksi alam, kuliner khas, kerajinan tangan dan cendramata, dan penginapan. (Sulistyani, 2016)

Nuryanti menjelaskan ada dua konsep utama dalam komponen desa wisata, yaitu: (Made Heny Urmila Dewi, 2013)

1. Akmodasi. Pengembangan dari tempat tinggal penduduk yang ditujukan untuk pengunjung agar mendapatkan kesan tinggal di desa.

2. Atraksi. Segala bentuk komponen fisik (setting lokasi, pemandangan alam, dsb) dan komponen non fisik desa (kegiatan masyarakat, upacara adat, dsb) yang ditujukan kepada pengunjung agar tertarik dan dapat berpartisipasi aktif.

\section{Metode Penelitian}

Metode penelitian dimulai dari pemilihan studi kasus desa wisata yang memungkinkan untuk menjawab permasalahan yang timbul diawal pembahasan. Lalu, segala bentuk pengambilan data dilakukan dengan observasi secara langsung dan tinjuan literatur. Data primer dan sekunder yang telah dikumpulkan, dipilih yang berkaitan dengan ide penelitian untuk selanjutkan dianalisis menggunakan komponen analisis berupa prinsip-prinsip arsitektur neo vernacular, diantaranya: hubungan langsung, hubungan abstrak, hubungan kontemporer, hubungan lanskap, dan hubungan masa depan. Analisis menggunakan Teknik deskriptif. 


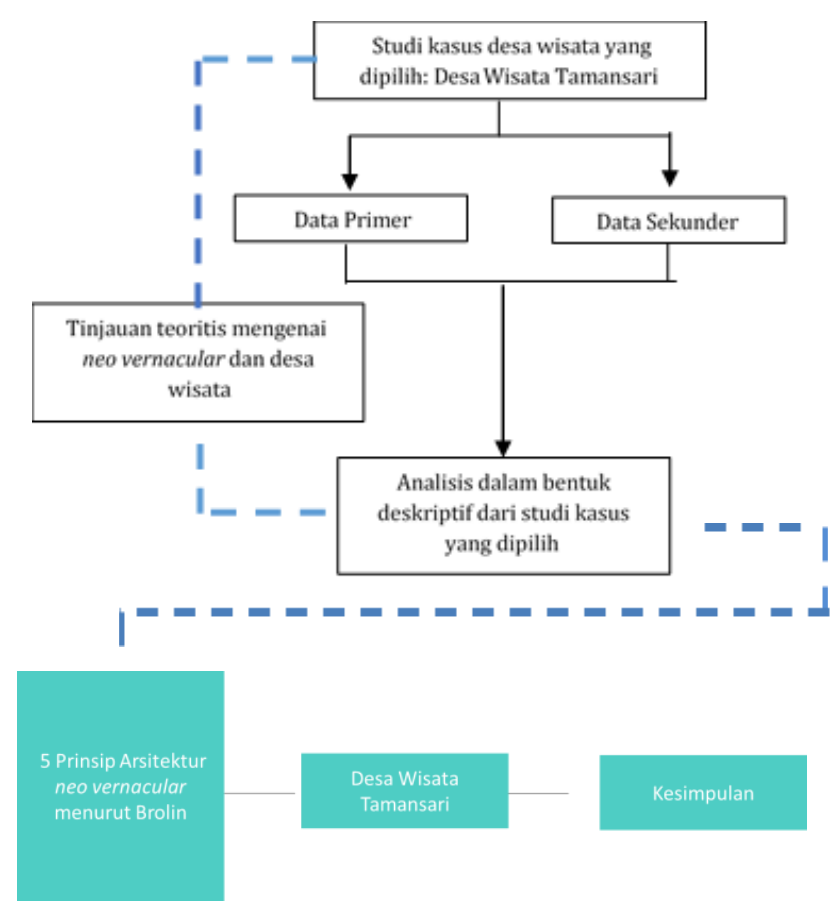

Gambar 2. Metode Penelitian

Sumber: Pribadi, 2019

Adapun variabel yang menjadi bahasan analisis 5 prinsip arsitektur neovernacular menurut Brolin, meliputi pembangunan tata ruang luar desa, pembangunan ekonomi, sosial, budaya yang berdampak terhadap sebuah fungsi bangunan atau ruang, dan pembangunan yang mengadaptasi segala bentuk kemajuan zaman dan teknologi.

\section{Hasil dan Pembahasan}

Desa Tamansari memiliki luas daerah kurang lebih $936 \mathrm{Ha}$ yang terdiri dari 9 RW dengan 37 RT. Desa Tamansari terletak lebih dekat dengan kaki gunung salak dan berbatasan langsung dengan taman nasional gunung salah di bagian selatan. Desa Tamansari berbatasan dengan daerah lain diantaranya:

- Utara dengan Desa Pasir Eurih

- Selatan dengan Taman Nasional Gunung Salak

- Timur dengan Desa Sukamantri dan Pasir Eurih

- Barat dengan Desa Sukajadi

Karena letaknya yang lebih dekat dengan Gunung Salak, topografi wilayahnya menjadi lebih ekstrem. Sudut kemiringan di jalan-jalan utama desa dapat mencapai 45 derajat bahkan lebih. Gambar dibawah adalah gambar jalan utama di Desa Wisata Tamansari yang menghubungkan Desa Tamansari dengan batas Desa Pasir Eurih.

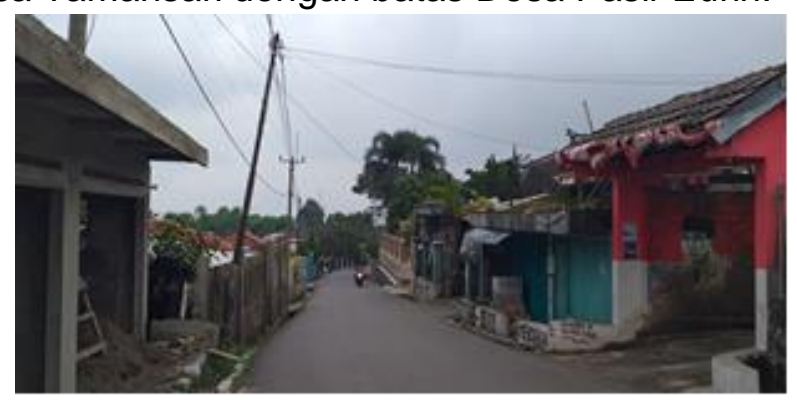

Gambar 3. Jalan Utama Desa Tamansari Sumber: Pribadi, 2019 
Kondisi topografi yang curam tersebut tertolong dengan kondisi jalan yang sudah cukup baik, jalan sudah beraspal dan cukup lebar. Lampu penerangan jalan sudah terpasang dengan cukup baik, lebar jalan kurang lebih 4 meter dan cukup untuk dilalui dua jalur mobil ukuran sedang. Kendaraan umum utama yaitu angkot dapat ditemukan walaupun jarang, sehingga mayoritas warga berpergian dengan menggunakan kendaraan pribadi seperti motor atau dengan berjalan kaki.

Warga-warga yang berkegiatan disekitar jalan utama desa, biasanya mereka yang pergi bekerja seperti berkebun, menambang pasir, dan mencari kayu menggunakan mobil ataupun motor. Kedaraan bermotor tersebut melaju dengan kecepatan pelan menuju sedang karena banyak juga anak-anak ataupun warga lain yang berjalan kaki di bahu jalan. Anak-anak bermain secara beramai-ramai menuju lapangan yang ada dibeberapa titik desa. Lampu-lampu penerangan di jalan utama telah terpasang dengan baik, fasilitias umum seperti sarana kesehatan, hiburan, warung-warung, tempat mengurus administrasi desa dibangun linier dengan pembangunan jalan. Begitu juga dengan rumah-rumah warga yang dibangun sejalan dengan jalan-jalan utama, dengan memperhatikan tingkat kelandaian tanah yang ada. Sayangnya, wilayah yang cukup curam belum bisa diolah dengan baik sehingga dibiarkan ditumbuhi dengan rumput dan tumbuhan-tumbuhan liar.

\section{Daya tarik Desa Wisata Tamansari diantaranya:}

- Kerajinan tanaman hias.

Sudah lama Desa Wisata Tamansari menjadikan kerajinan tanaman hias sebagai sebuah ciri khas desa. Mayoritas warga yang didominasi dengan ibu rumah tangga bercocok tanam tanaman hias di halaman rumahnya. Ada juga yang sengaja membuat rumah khusus bercocok tanam. Banyak juga yang membiarkan tanaman hias tersebut ditanam di halaman rumah tanpa dipagari sehingga tidak hanya mendapat keuntungan dari penjualanya tetapi juga menambah keindahan jalan.

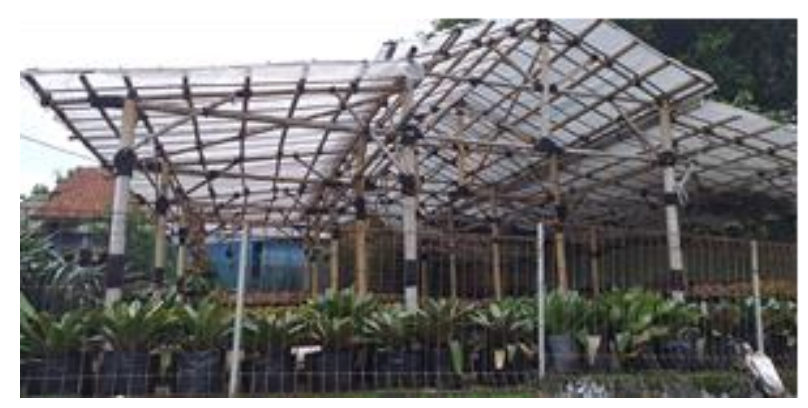

Gambar 4. Rumah Tanaman Hias

Sumber: Pribadi, 2019

- Wisata "Popoho" dan kebun karet.

Popoho berasal dari Bahasa sunda yang berarti lalapan. Lalapan adalah sejenis sayursayuran yang biasa disajikan dengan makanan utama, sayuran dimakan langsung tanpa harus diolah terlebih dahulu. Jenis-jenis yang beragam tumbuh di Desa Wisata Tamansari di wilayah perbatasan dengan daerah Gunung Salak. 


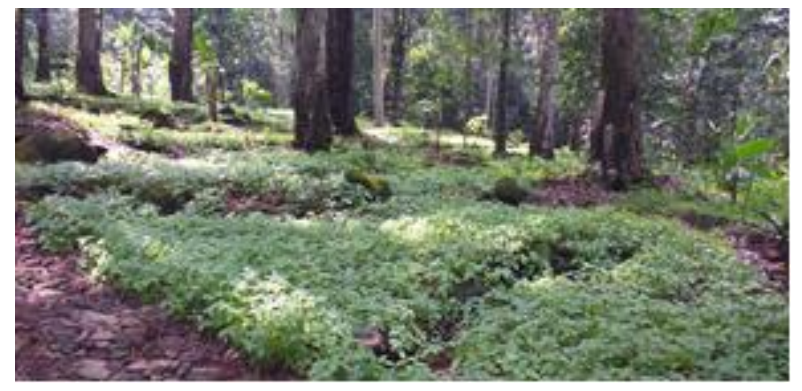

Gambar 5. Tumbuhan Popoho

Sumber: Pribadi, 2019

- Pura Parahyangan Agung.

Pura Parahyangan Agung merupakan Pura terbesar yang ada di Jawa Barat. Umat Hindu yang tersebar di daerah Jawa Barat rutin berkunjung kesini untuk melaksanakan ibadah sembahyang. Dibangun diatas bukit, Pura Parahyangan Agung memberikan pemandangan yang sangat indah khas pegunungan dan asrinya sebuah desa. Umat Hindu meyakini bahwa dahulu disini tempat Prabu Siliwangi dan pasukan nya mencapai "moksa".

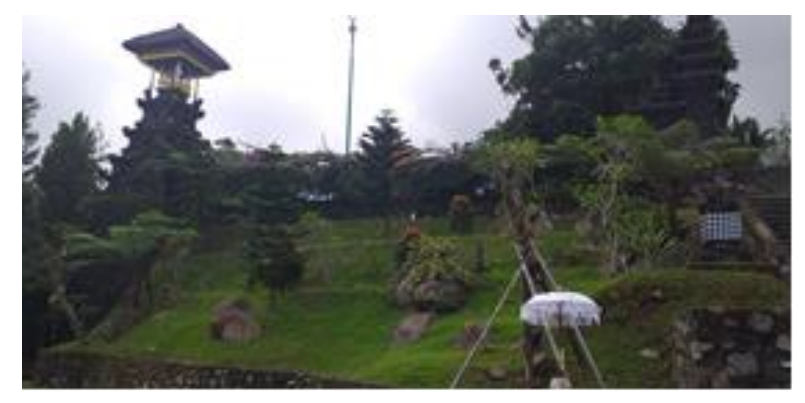

Gambar 6. Pura Parahyangan Agung

Sumber: Pribadi, 2019

- Situ Tamansari.

Situ Tamansari menjadi objek wisata yang wajib dikunjungi di Desa Wisata Tamansari. Pasalnya situ ini menjadi sebuah saksi bisu sejarah dan perkembangan daerah-daerah lain di Desa Tamansari. Situ Tamansari terletak di pusat desa dan memiliki beberapa lapangan terbuka di sudut-sudutnya. Bila sedang tidak ada kegiatan desa, situ biasa dipakai warga untuk memancing ikan. Sayangnya, kondisi terkini Situ Tamansari kurang terawat. Sarana permainan air seperti perahu bebek ataupun outbond tidak terlaksana seperti beberapa tahun kebelakang. Sekarang, warga banyak menggunakan lapangan di sekeliling situ untuk kegiatan seperti upacara pernikahan.

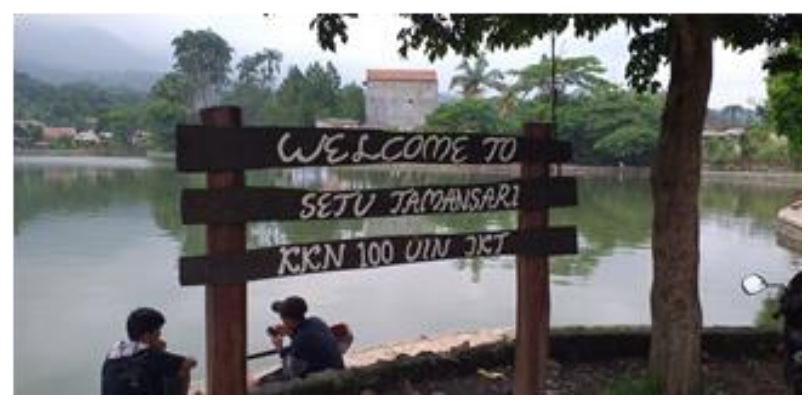

Gambar 7. Situ Tamansari

Sumber: Pribadi, 2019 


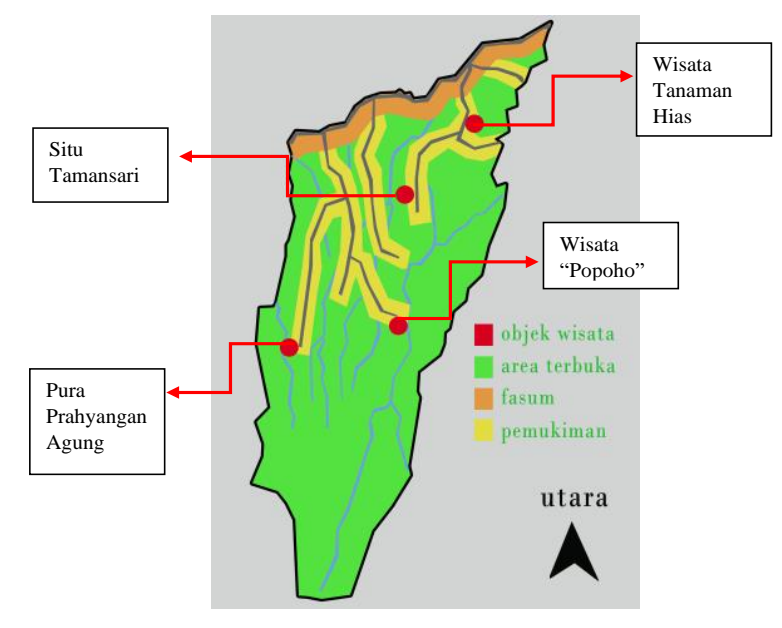

Gambar 8. Sebaran Wisata Desa

Sumber: Pribadi, 2019

\section{Analisis Lima Prinsip Arsitektur Neo Vernacular:}

1. Hubungan Langsung:

Pada Desa Wisata Tamansari, bangunan-bangunan dengan fungsi baru dapat ditemukan terutama di zonasi fasilitas umum. Bangunan kantor desa yang berfungsi sebagai tempat mengatur administrasi desa, pusat kesehatan masyarakat desa, rumah-rumah toko (ruko) yang menjual barang-barang keperluan sehari-hari terletak sepanjang jalan pembatas desa. Baik pemerintah desa maupun masyarakat desa membangun bangunan dengan fungsi baru seiring dengan kemajuan zaman.

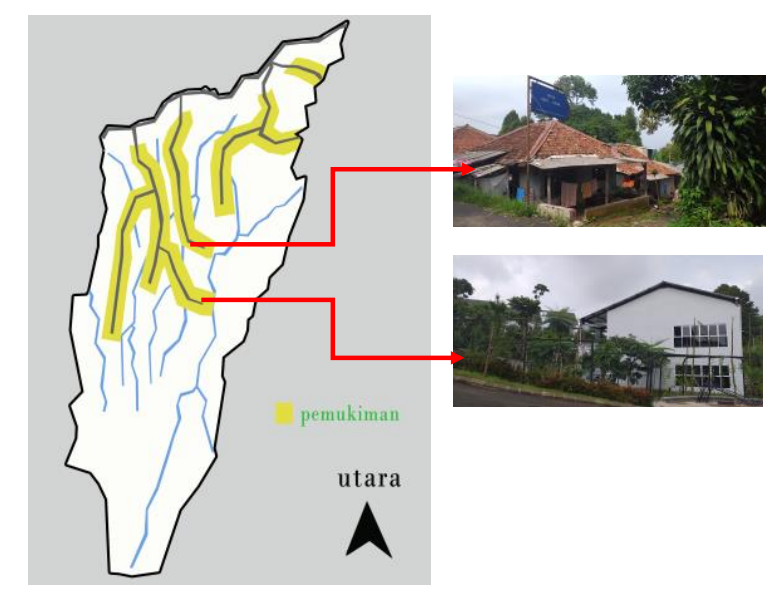

Gambar 9. Zona Permukiman Desa Sumber: Pribadi, 2019

Pembangunan yang terjadi di Desa Tamansari lebih kearah organik dan tercipta tanpa guide lines yang mengikat. Meskipun begitu, pembangunan yang terjadi tersebut masih bernilai kontekstual dengan lingkungan dan kebiasaan. Misalnya pembangunan rumah rumah penduduk di sepanjang jalan utama desa yang bersandingan dengan rumah budidaya tanaman hias.Agar menciptakan keterkaitan dengan lingkungan, pebudidayaan tanaman hias terkadang dilakukan ditempat-tempat terbuka yang langsung berbatasan dengan jalan, terkadang juga lahan kosong yang tidak memungkinkan untuk dibangun juga ditanami tanaman hias guna menambah nilai kontekstualitas dengan alam yang indah. 


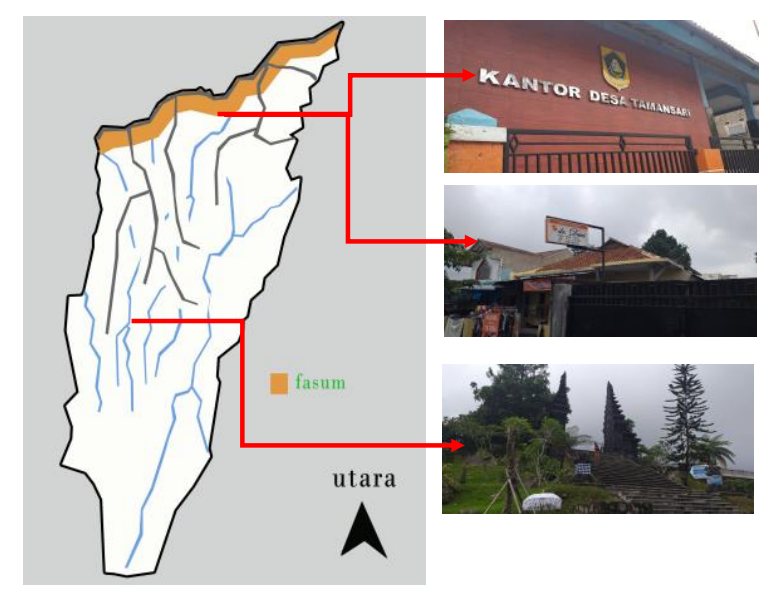

Gambar 10. Zona Fasilitas Umum Desa Sumber: Pribadi, 2019

2. Hubungan Abstrak

Hubungan antara kebudayaan dan nilai-nilai lokalitas di Desa Tamansari terlihat bila ada pengunjung yang ingin melihat atraksi budaya sunda di Desa Wisata Tamansari, pihak desa wisata akan memanggil sanggar kesenian sunda dari Desa Wisata Pasir Eurih. Hasilnya, ruang yang tercipta karena hal tersebut dapat berupa ruang terbuka seperti lapangan ataupun ruang tertutup seperti aula.

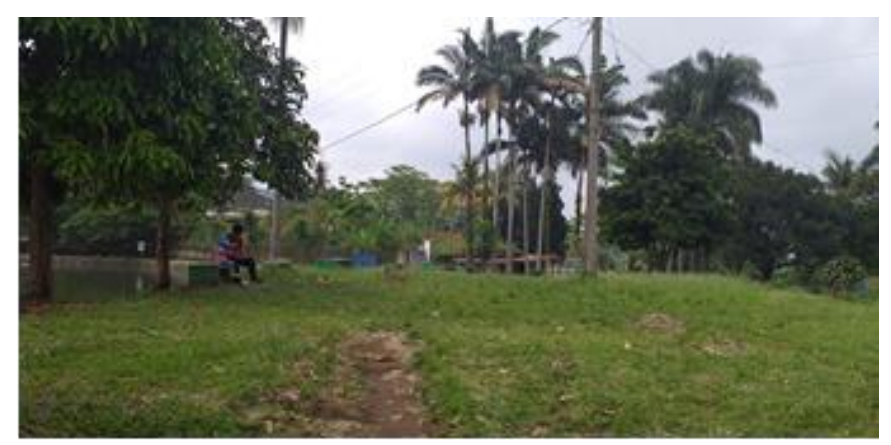

Gambar 11. Ruang Terbuka Desa

Sumber: Pribadi, 2019

Pembangunan yang semakin gencar kini terfokus kepada kenyamanan dan kebutuhan hidup saat ini. Meski begitu, peninggalan arsitektur di Desa Tamansari dapat ditemukan. Salah satunya adalah Bangunan Pura Parahyangan Agung.

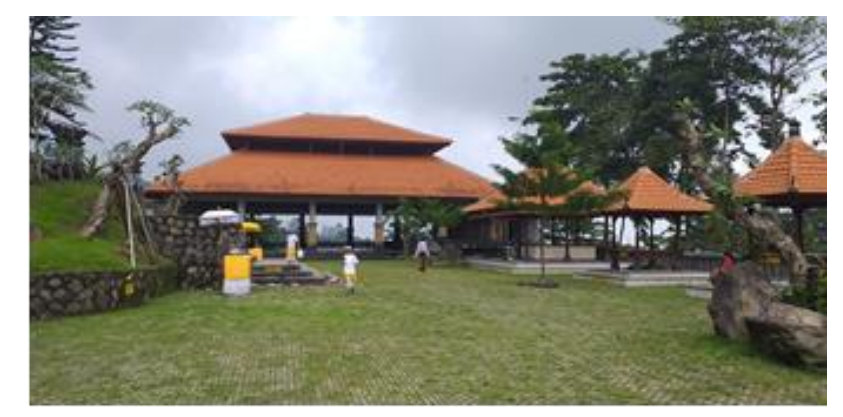

Gambar 12. Pendopo Pura Prahyanganan Agung Sumber: Pribadi, 2019 
Bangunan pendopo di area bawah tempat sembahyang berupa bangunan tanpa dinding. Sebuah pendopo besar yang dapat digunakan sebagai Gedung serba guna dapat digunakan kegiatan pura ataupun desa wisata. Atap limasan dengan bahan genting tanah liat, ukiran-ukiran di langit-langit bagian dalam pendopo menunjukan ciri khas sunda.

Tabel1. Ragam hias alam

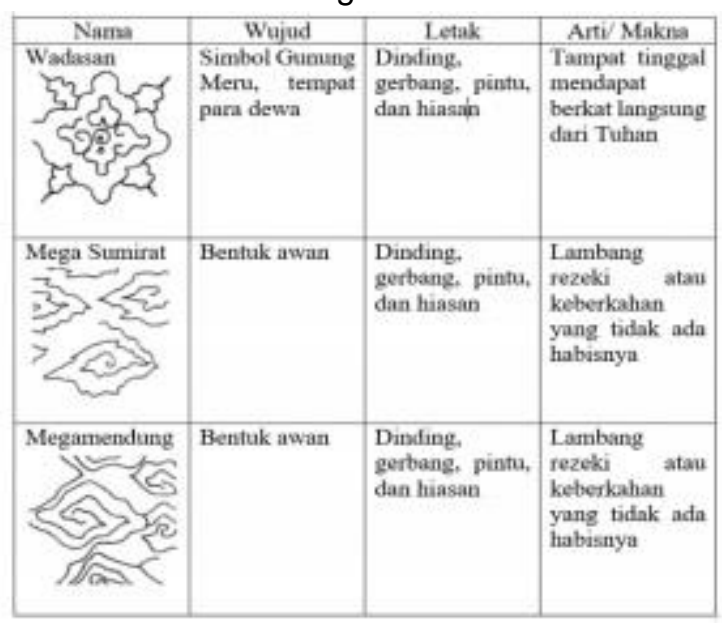

Sumber: Saputra, 2019

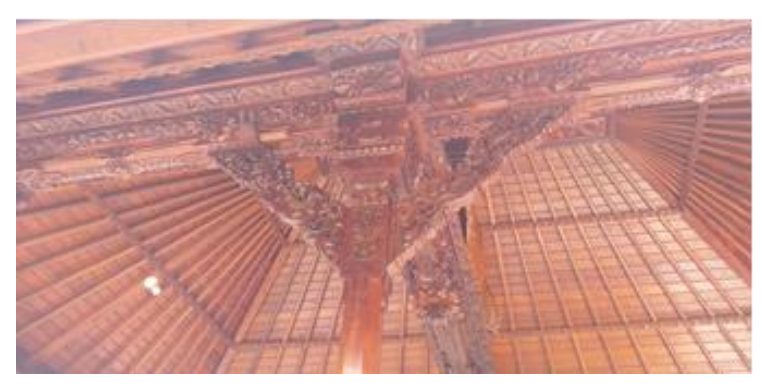

Gambar 13. Pendopo Pura Prahyanganan Agung Sumber: Pribadi, 2019

Ukiran pada kayu penopang pendopo dapat ditemukan dan merupakan bentuk asimilasi budaya antara sunda dengan hindu. Corak-corak tersebut banyak ditemukan dan menjadi sebuah tipologi yang unik, karena Pura Parahyangan Agung merupakan pura terbesar yang ada di Jawa Barat. Berbeda dengan pura yang ada di Bali yang menggunakan naga sebagai lambing dari banyak pura disana, simbol macan putih yang merupakan lambang dari Prabu Siliwangi menghiasi banyak patung-patung di Pura Parahyangan Agung.

\section{Hubungan Kontemporer}

Pembangunan yang terjadi di Desa Tamansari tidak lagi konvensional seperti zaman dulu. Penggunaan teknologi terbaru dalam system struktur, system drainase bangunan ataupun wilayah sudah menggunakan teknologi yang kontemporer. Bata merah atau hebel yang disemen, diikat dengan kolom-kolom berisi tulangan besi campuran beton menjadi bahan utama penyusun struktur hampir semua rumah-rumah tempat tinggal warga. Penggunaan kayu dengan atap jerami digunakan pada bangunan-bangunan kecil sederhana seperti gazebo tempat jaga warga. 


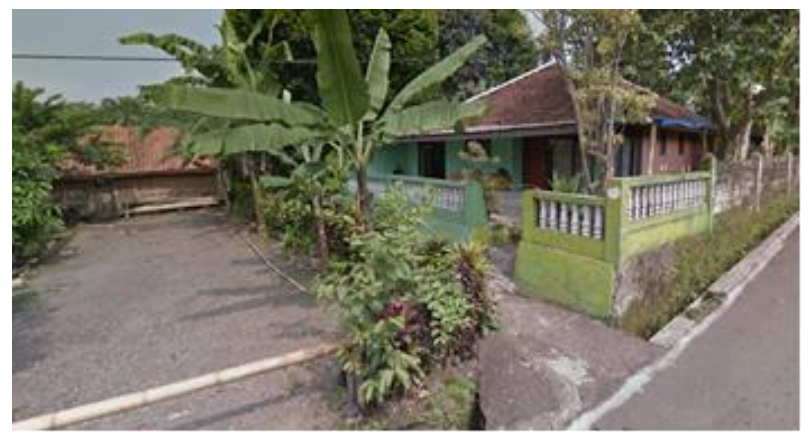

Gambar 14. Salah satu rumah warga desa Sumber: Pribadi, 2019

Gambar salah satu rumah warga yang sudah menggunakan bahan-bahan kontemporer. Selain rumah warga, salah satu peninggalan arsitektur yang ada di Desa Wisata Tamansari yaitu Pura Hindu Parahyangan Agung juga sudah menggunakan teknologi baja pada bagian kuda-kuda atap pendoponya.

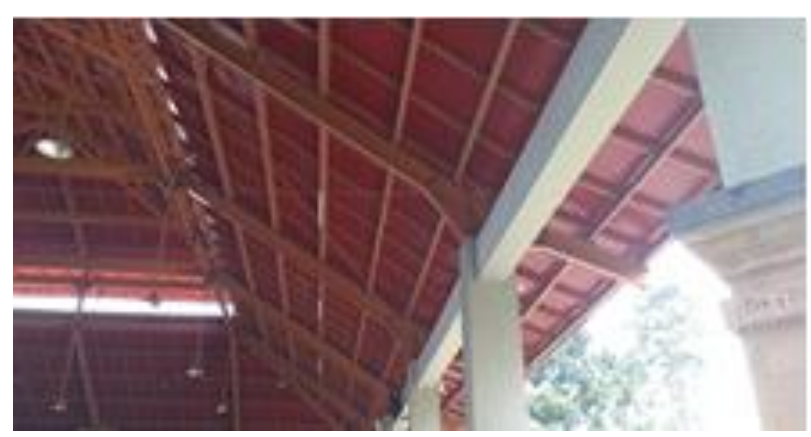

Gambar 15. Salah satu rumah warga desa Sumber: Pribadi, 2019

Bentuk atap limasan berundak dengan bahan penutup genting tanah liat ditopang dengan kuda-kuda baja yang mencerminkan prinsip hubungan kontemporer pada bangunan pendopo Pura Parahyangan Agung di Desa Wisata Tamansari.

4. Hubungan Lansekap

Keadaan bangunan-bangunan di Desa Sukajadi mengadaptasi iklim tropis kaki gunung. Komponen adaptasi terlihat mulai dari pondasi, dinding, hingga atap. Rumah juga terdapat banyak bukaan dengan ukuran sedang, dan atap dengan tritisan Panjang dengan bahan tanah liat atau seng.

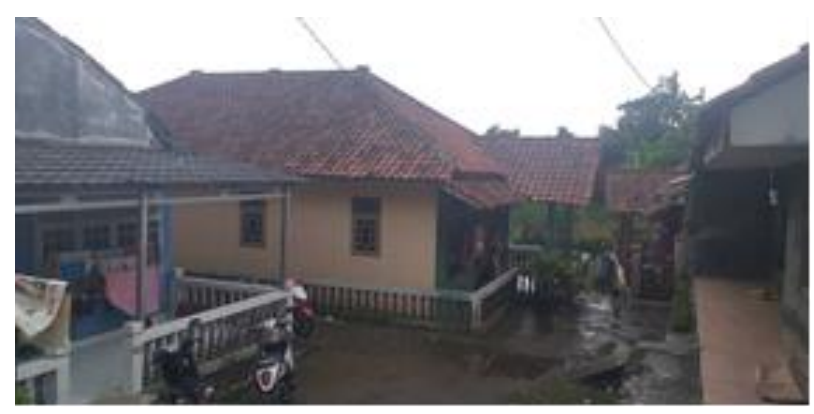

Gambar 16. Adaptasi terhadap iklim Sumber: Pribadi, 2019 
Pembangunan kearah utara yang dominan dengan kontur yang tidak begitu ekstrem bila dibandingkan kearah selatan. Mulai dari jalan utama yang terhenti ditengah-tengah desa, bangunan-bangunan rumah penduduk juga memiliki jarak yang jauh satu sama lain agar mendapatkan lahan yang datar. Pembangunan rumah penduduk linier sejalan dengan jalan utama

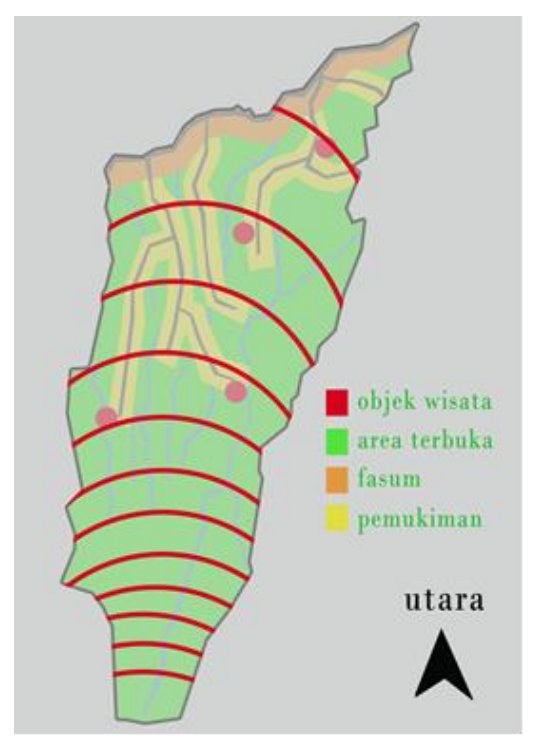

Gambar 17. Topografi Desa Tamansari Sumber: Pribadi, 2019

5. Hubungan Masa Depan

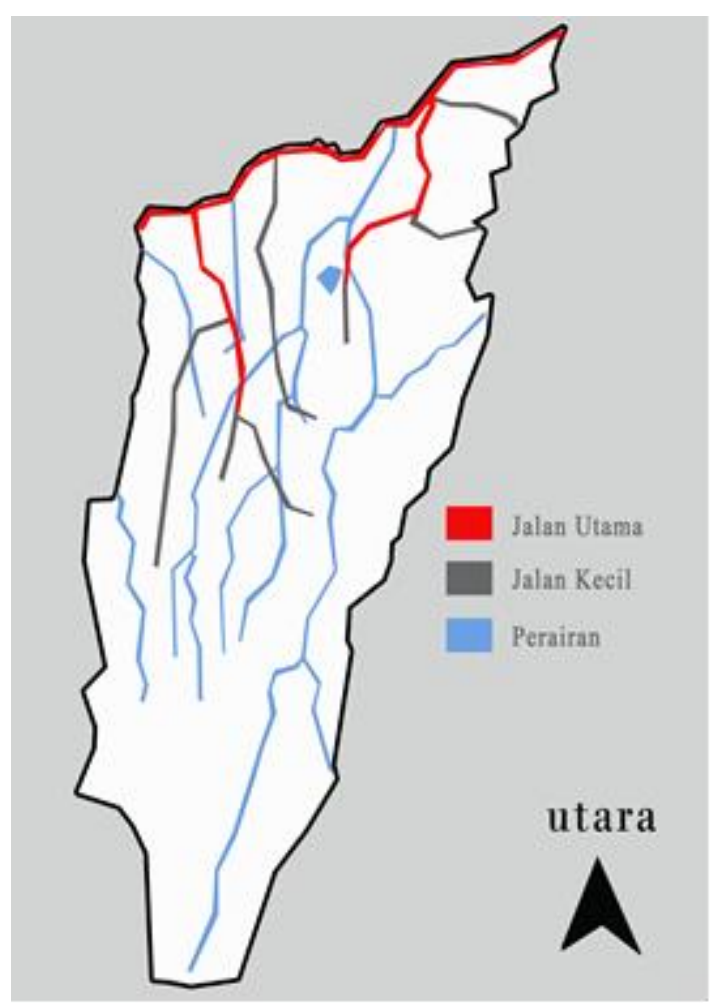

Gambar 18. Jaringan jalan dan air Desa Tamansari Sumber: Pribadi, 2019 
Tamansari. Dapat terlihat bahwa jaringan jalan utama desa berada pada wilayah utara desa sampai menuju ke bagian tengah desa. Hal tersebut terjadi dikarenakan wilayah desa yang berbatasan langsung dengan Taman Nasional Gunung Salak pada bagian selatan yang menciptakan topografi yang semakin ekstrem. Jalur utama tersebut berukuran lebar kurang lebih empat meter dan dapat dilalui dua jalur kendaraan roda empat berukuran sedang. Jalan utama dilalui oleh kendaraan umum berupa angkot namun berhenti ditengah wilayah desa lalu dilanjutkan dengan jalan kecil yang hanya dapat diakses dengan kendaraan roda dua atau berjalan kaki. Pembangunan jalan tersebut mempertimbangkan keadaan wilayah dan realitas masa yang akan datang. Ketika pengunjung Desa Wisata Tamansari hendak mengunjungi objek wisata Popoho atau Pura Parahyangan Agung, jalan utama yang tidak diteruskan mengharuskan pengunjung untuk berhenti dan melanjutkan perjalanan ke atas dengan berjalan kaki memberikan pengalaman dan kesan tersendiri bagi pengunjung.

\section{Kesimpulan}

Dari analisis yang telah dilakukan dengan menggunakan poin-poin analisis berupa prinsip-prinsip arsitektur neo vernacular. Dapat disimpulkan bahwa Desa Wisata Tamansari berkembang dengan baik sesuai perkembangan zaman yang disesuaikan dengan kebiasaan, nilai-nilai lokalitas, dan kebudayaan yang ada di dalam desa. Segala prinsipprinsip arsitektur neo vernacular ditemukan dan diakomodasi dengan baik tercermin dari ruang-ruang desa yang tercipta karenanya.

Desa Wisata Tamansari menciptakan pembangunan desa yang sejalan dengan perkembangan zaman disamping menjaga nilai-nilai lokalitas dan budaya. Hal tersebut ditunjukkan pada pembangunan yang linier dan mengantisipasi iklim dan kontur, penerapan ornamen yang masih terjaga, dan melestarikan daerah resapan air sebagai implementasi prediksi keadaan masa depan

\section{Daftar Pustaka}

Abdul aziz arrosyid, s. ,. (2016). Museum songket palembang dengan pendekatan arsitektur neo-vernakular . Arsitektura, vol. 14, no.2, oktober 2016.

Erdiono, d. (november 2011). Arsitektur 'modern' (neo) vernacular di indonesia. Jurnal sabua vol. 3, no.3, 32-39.

Eva anggraini, w. S. (april 2016). Sentra usaha kecil menengah dengan pendekatan arsitektur neo vernakular di surakarta. Arsitektura, vol. 14, no.1.

Ghina fajrine, a. B. (2017). Penerapan konsep arsitektur neo vernakular pada stasiun pasar minggu. Seminar nasional cendekiawan ke 3 tahun 2017, 85-91.

Hermawan, h. (september 2016 ). Dampak pengembangan desa wisata nglanggeran terhadap ekonomi masyarakat lokal . Jurnal pariwisata, vol. lii no. 2, 105-117.

Made heny urmila dewi, c. F. (2013). Pengembangan desa wisata berbasis partisipasi masyarakat lokal di desa wisata jatiluwih tabanan, bali. Kawistara, vol.3, no.2, 117226.

Mohammad sahril adhi saputra, a. F. (2019). Kajian arsitektur tradisional sunda pada desain resort. Jurnal arsitektur purwarupa volume 03 no 4, 65-73.

Rachmawati, m. (2010). Humanisme (kembali) dalam arsitektur. Nalars volume 9 nomor 2 juli $2010: 103-116,103-116$.

Sulistyani, a. M. (2016). Pengembangan desa wisata berbasis eko-budaya. Jurnal festiva, volume 1 , nomor 2, 39-48. 
Windra dwi saputra, w. S. (2019). Penerapan arsitektur neo-vernakular batak pada fasad bandar udara domestik di kabupaten dairi sumatera utara . Jurnal senthong, 647658. 